\title{
Relative efficiencies of the Burkard 7-Day, Rotorod and Burkard Personal samplers for Poaceae and Urticaceae pollen under field conditions
}

\author{
Robert G. Peel ${ }^{1,2}$, Roy Kennedy2, Matt Smith ${ }^{2,3}$, Ole Hertel ${ }^{1,4}$ \\ ${ }^{1}$ Department of Environmental Science, Aarhus University, Roskilde, Denmark \\ ${ }^{2}$ National Pollen and Aerobiology Research Unit, University of Worcester, Worcester, UK \\ ${ }^{3}$ Department of Otorhinolaryngology, Medical University of Vienna, Vienna, Austria (present affiliation) \\ ${ }^{4}$ Department of Environmental, Social and Spatial Change (ENSPAC), Roskilde University, Roskilde, Denmark
}

Peel RG, Kennedy R, Smith M, Hertel O. Relative efficiencies of the Burkard 7-Day, Rotorod and Burkard Personal samplers for Poaceae and Urticaceae pollen under field conditions. Ann Agric Environ Med. 2104; 21(4): 745-752. doi: 10.5604/12321966.1129927

\begin{abstract}
Introduction. In aerobiological studies it is often necessary to compare concentration data recorded with different models of sampling instrument. Sampler efficiency typically varies from device to device, and depends on the target aerosol and local atmospheric conditions. To account for these differences inter-sampler correction factors may be applied, however for many pollen samplers and pollen taxa such correction factors do not exist and cannot be derived from existing published work.

Materials and methods. In this study, the relative efficiencies of the Burkard 7-Day Recording Volumetric Spore Trap, the Sampling Technologies Rotorod Model 20, and the Burkard Personal Volumetric Air Sampler were evaluated for Urticaceae and Poaceae pollen under field conditions. The influence of wind speed and relative humidity on these efficiency relationships was also assessed. Data for the two pollen taxa were collected during 2010 and 2011-2012, respectively.

Results. The three devices were found to record significantly different concentrations for both pollen taxa, with the exception of the 7-Day and Rotorod samplers for Poaceae pollen. Under the range of conditions present during the study, wind speed was found to only have a significant impact on inter-sampler relationships involving the vertically-orientated Burkard Personal sampler, while no interaction between relative efficiency and relative humidity was observed.

Conclusions. Data collected with the three models of sampler should only be compared once the appropriate correction has been made, with wind speed taken into account where appropriate.
\end{abstract}

Key words

Aerobiology, bioaerosol sampler, correction factor, grass pollen, relative efficiency

\section{INTRODUCTION}

The Burkard 7-Day Recording Volumetric Spore Trap (7-Day sampler) is a single stage slit impactor based on the classical design of Hirst [1], and as such is one of several models of 'Hirst-type' sampler. It has become the standard pollen and fungal spore monitoring device in Europe and the USA [2,3], and has been adopted by many European national pollen monitoring networks, including all monitoring stations that contribute to the European Aeroallergen Network [4, p. 12]. The size, weight, power requirements and design of the 7-Day sampler, however, render it unsuitable for many field situations in which portability is often a limiting factor. The Sampling Technologies Rotorod Sampler Model 20 (Rotorod) and the Burkard Personal Volumetric Air Sampler (PVAS) are small, lightweight, battery operated bioaerosol samplers that can be easily deployed in many environments. The efficiency of all three devices is known to vary with aerosol aerodynamic characteristics, including size, shape and density, as well as with ambient wind speed $[5,6]$.

Address for correspondence: Robert Peel, Department of Environmental Science, Aarhus University, Frederiksborgvej 399, 4000 Roskilde, Denmark

E-mail: rp@envs.au.dk

Received: 23 November 2012; accepted: 21 May 2013
In pollen exposure studies it is common practice to compare monitoring station data recorded with a Hirst-type sampler with exposure data collected in the microenvironment of a study subject using a portable device $[7,8,9,10,11]$. Data collected with different instruments, however, can only be meaningfully reconciled if the efficiency relationship between the two devices is known. Theory concerning the efficiency of generic aerosol sampling heads related to the 7-Day sampler and PVAS is well established for idealised conditions [12]; however, in the case of the 7-Day sampler, theory does not agree with experimental data (most likely because it does not account for the influence of the sampler's bulky housing on local air flow [1]), while there appears to be no empirical PVAS data with which to validate existing efficiency models. Commonly used theoretical models also fail to fully account for the effects of particle size and wind speed on the efficiency of rotating-arm samplers such as the Rotorod [6]. While the efficiency of Hirst-type and rotating arm samplers has been established for grass pollen through wind tunnel studies $[13,14]$, results obtained under laboratory conditions do not necessarily translate to the outdoor environment. Turbulence is thought to affect the efficiency both of rotating arm samplers [6] and, through the misalignment of inlet and mainstream air flow, also Hirst-type samplers $[15,16]$. The current body of published work is thus patchy and incomplete, and in particular - as far as the authors are aware - does not 
establish the relative efficiency of these three devices under field conditions for either Poaceae or Urticaceae pollen, two of the taxa responsible for pollen allergy in Europe [17].

Pollen grains are hygroscopic and have been shown to dry-out following emission at a rate related to ambient relative humidity, leading to changes in their size, shape and density $[18,19]$ - indeed wet Phleum pratense pollen grains have been reported to weigh twice as much as dry grains [20]. Ambient relative humidity then potentially influences sampler efficiency; however, this does not appear to have been taken into consideration in previous investigations.

Objective. The objective of this study was to investigate the efficiency of the 7-Day sampler compared to those of the Rotorod and PVAS under field conditions for Poaceae and Urticaceae pollen, to assess the influence of wind speed and relative humidity on these relationships, and to derive appropriate correction factors. For completeness, the efficiencies of the two mobile samplers were also compared.

\section{MATERIALS AND METHOD}

Sampling instruments. The 7-Day sampler (Fig. 1) is a volumetric single-stage slit impactor. Air is aspirated through a horizontally orientated $2 \times 14 \mathrm{~mm}$ slit at a rate of $101 \mathrm{~min}^{-1}$, and impacted against an adhesive tape that moves continuously past the slit at a rate of $2 \mathrm{~mm} \mathrm{hour}^{-1}$. The tape is usually assayed by counting the number of pollen grains along a single transverse transect that is typically $\leq 0.5 \mathrm{~mm}$ wide (the width of the field of view of a standard light microscope at magnification $\times 400$ ). Each transect thus corresponds to a discrete section of a continuously collected sample trace, with each transverse line across the transect exposed for 1 hour. The entire transect corresponds to a sample collected over slightly more than one hour, the precise duration depending on the width of the transect. A detailed account is given in the British Aerobiology Federation's trapping guide [21]. The sampler's inlet is kept facing into the wind by means of a wind vane, allowing for so-called isoaxial sampling. Burkard 7-Day samplers are frequently the reference device against which bioaerosol sampler performance is assessed [22, 23, 24].
The PVAS is also a volumetric single-stage slit impactor. Sample collection is achieved through the same principle as for the 7-Day sampler; however, in the case of the PVAS, air is aspirated through a vertically-orientated bell-shaped inlet that tapers to a $1 \times 14 \mathrm{~mm}$ slit, while the collection substrate, a microscope slide typically coated with an adhesive medium, is static and thus produces discrete data. The PVAS has a throughput of $101 \mathrm{~min}^{-1}$, and may be operated either from an internal battery or through mains power. It was designed for the indoor environment, however its compact and uncomplicated design has led to its use in a number of outdoor studies [7, 25, 26].

Rotating arm impactors have been used for routine monitoring, but are perhaps more commonly employed as field instruments, for example [10, 27, 28, 29]. The Model 20 is one of two Rotorod models currently produced commercially. Samples are collected on a pair of $1.52 \mathrm{~mm}$ wide polystyrene collector rods which are rotated through the air at 2,400 rpm. The leading edge of each rod is coated with a user applied adhesive, usually silicone grease, which serves to trap impacted particles, producing discrete data. The volume of air sampled can be calculated rendering this device volumetric, with a single rod sampling air at a rate of $21.7 \mathrm{~min}^{-1}$. The sampler may be run from an external $12 \mathrm{~V}$ battery or alternatively from mains power [30].

Experimental sites. The study was performed at two different sites over three years, however the methods employed were equivalent. Urticaceae data were collected at the University of Worcester, UK, during August 2010. The three samplers were set up in a linear array on the large flat roof of the Institute of Science and the Environment, $9.5 \mathrm{~m}$ above ground level, with the 7-Day sampler in the middle and the two mobile samplers approximately $1 \mathrm{~m}$ to either side. All three instruments were a minimum of $4.5 \mathrm{~m}$ from the edge of the roof. The 7-Day sampler is part of the UK national pollen monitoring network and is in continuous operation all year round. It stands on a concrete plinth with its orifice $1.22 \mathrm{~m}$ above the roof. The Rotorod was mounted on a vertical stand and the PVAS in a specially designed cup-shaped holder on top of a tripod, with the sampling points of both devices at the height of the 7-Day sampler's inlet. Weather data were collected with a
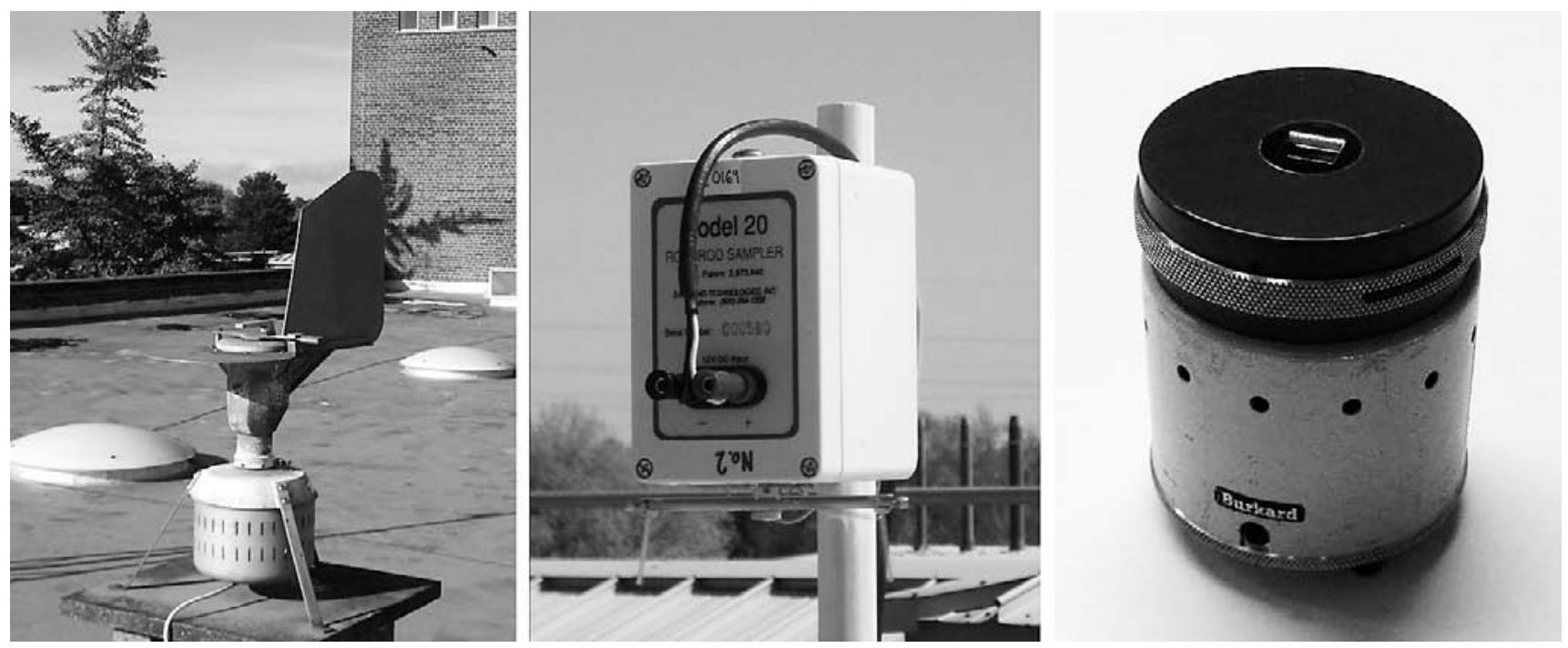

Figure 1. The three bioaerosol samplers used in the study: 7-Day sampler (left), Rotorod (middle) and PVAS (right) 
Davis Vantage Pro 2 weather station (anemometer sensitivity $1 \mathrm{~ms}^{-1}$ ) positioned approximately $10 \mathrm{~m}$ from the sampler array and $2 \mathrm{~m}$ above the roof.

Poaceae data were collected at the Danish Meteorological Office (DMI) in North-West Copenhagen, Denmark, during May and June 2011 and 2012. The samplers were set up on the flat platform that constitutes the eastern corner of the roof, $15 \mathrm{~m}$ above ground level. Due to space restrictions the samplers were set up in a triangular array, approximately $1 \mathrm{~m}$ apart and at least $1.2 \mathrm{~m}$ from the edge of the roof. The 7-Day sampler is part of the permanent Danish pollen monitoring network and is typically in continuous operation from January - September. It is mounted on a stand with its orifice $1 \mathrm{~m}$ above the roof. The two mobile samplers were mounted in the manner described above. Wind speed data were collected with a switching anemometer (Vector Instruments A100R, sensitivity $0.2 \mathrm{~ms}^{-1}$ ) mounted above the Rotorod in such a way that the anemometer cups were $30 \mathrm{~cm}$ from the sampler's rotating arm, and relative humidity was recorded at the start and end of each sample collection using a hand held thermohygrometer (Omega RH82).

Data collection and processing. The Rotorod and PVAS samplers were run concurrently for periods of 58 minutes. Corresponding data were obtained from the 7-Day sampler trace, thus sets of concurrent, approximately hour-averaged data were acquired for the three sampler models. Houraveraged pollen data can be usefully compared with meteorological data, which varies from hour-to-hour.

Samples were collected on selected days when pollen concentrations were expected to be high (i.e. warm, precipitation free and during the flowering season of the target plant taxa), and at times of the day when peak concentrations were anticipated. In all, 41 sets of Urticaceae samples and 128 sets of Poaceae samples were collected. The number of hours each year for which Poaceae pollen concentrations recorded at the DMI monitoring station are high is typically small. As an example, during 2011 the routine bi-hourly concentration data recorded at the monitoring station exceeded 100 grains $\mathrm{m}^{-3}$ on only 41 occasions. Predicting high concentrations is not easy, thus a large proportion of the Poaceae data were collected under low concentrations. To ensure results were of a high quality, data corresponding to concentrations $<85.5$ grains $\mathrm{m}^{-3}$ according to the 7 -Day sampler were rejected (equivalent to a count of $<10$ pollen grains), leaving only 45 sets of Poaceae data for statistical analysis. One set of Urticaceae samples was rejected due to rainfall during sample collection, leaving 40 sets for analysis.

The Rotorod was battery powered (Yuasa NP7-12) in both locations whilst the PVAS was battery powered in Worcester but mains powered in Copenhagen. All batteries were fully charged at the start of each day. The maximum period of continuous battery operation was 11 hours for the Rotorod, and 7 hours for the PVAS. The PVAS is programmed to emit a warning siren when battery power becomes low enough to affect flow rate, but this never occurred during sample collection, while during a test run the rate of rotation of the Rotorod under battery power was found to have reduced by only $0.45 \%$ after 24 hours of continuous operation. At DMI, the Rotorod rotation and PVAS flow rates were measured at the start and end of each day using a digital tachometer (Farnell AT-6) and a Wright Respirometer (British oxygen type P. M., Ferraris Development \& Engineering), respectively.
The maximum deviation from the mean rate was $0.58 \%$ for the Rotorod and $4.83 \%$ for the PVAS. These data were not collected at the Worcester site. The flow rate of the 7-Day sampler was verified on a weekly basis in Worcester and on a daily basis in Copenhagen.

The 7-Day sampler in Worcester was fitted with a standard 7-day drum, and samples collected on Melinex tape coated with a 9:1 petroleum jelly/paraffin wax adhesive. This is the standard adhesive of the UK pollen monitoring network. The 7-Day sampler in Copenhagen was fitted with a 24-hour head assembly, with samples collected directly onto a slide coated with silicone solution (Lanzoni s.r.l.). These two adhesives have been shown to have statistically equivalent trapping abilities [31]; thus, the use of different adhesives does not introduce bias. In both locations, PVAS samples were collected on $18 \mathrm{~mm}$ pieces of Melinex tape coated with the petroleum jelly/paraffin wax adhesive. Samples collected with both the 7-Day sampler and PVAS were prepared for microscopic assay using a stain bearing glycerine jelly mountant, and processed according to the methods of the British Aerobiology Federation [21].

Rotorod collector rods were coated with the standard silicone grease adhesive in both locations. After exposure, the rods were stained with Calberla's solution, and mounted on a specially designed microscope stage adapter using the method described by the manufacturer [30]. For the Urticaceae data, all rods were assayed, while for the Poaceae data only one rod from each pair was assayed.

Samples from all three samplers were assayed under a light microscope at $\times 400$ or $\times 640$ magnification by the first author, and counts were converted to concentrations in pollen grains $\mathrm{m}^{-3}$ by dividing the number of pollen grains by the volume of air sampled. The numbers of Urticaceae pollen grains caught by the two Rotorod collector rods were found to be very strongly correlated (Spearman's coefficient $r_{s}=0.98$, one-tailed $\mathrm{p}<0.0005)$, and there was no evidence of bias between rods; therefore, for both pollen taxa concentrations were calculated based on only one rod from each pair' ${ }^{1}$. Meteorological data were aggregated into mean hourly values corresponding to pollen data averaging periods.

Analysis and statistical methods. The efficiency relationships between pairs of samplers were investigated by comparing concurrent concentrations measurements, while the influence of meteorological parameters on this relationship was investigated using ratios of these concentrations. The divisor in these ratios was the measurement made with the 7-Day sampler or (when comparing the two mobile devices) the Rotorod. Correlation analysis was used to assess the strength of these relationships. The Kolmogorov-Smirnov test for normality indicated that not all pollen datasets could be considered normally distributed, therefore, Spearman's correlation was used. Results were considered significant at the $95 \%$ level.

Inter-sampler conversion factors were determined by fitting regression lines through data scatter plots. Where wind speed was found to have a significant effect on the efficiency relationship, the dependent concentration ratio was regressed onto the independent wind speed variable using the least squares method. Relationships found to be independent of wind speed were parameterised by fitting geometric mean

1. A single rod samples air at $21.71 \mathrm{~min}^{-1}$, over twice the rate of the two suction devices $\left(101 \mathrm{~min}^{-1}\right)$ 
regression lines through the origin to concentration data [32]. Conversion factor performance was assessed using the root mean square relative error (RMSE), with errors scaled by the concentration according to the 7-Day sampler or (when comparing the two mobile devices) the Rotorod. All analysis was performed using MATLAB version 7.7.0.471 [33].

\section{RESULTS}

Concentration data for the three sampler pairings and two pollen taxa are plotted in Figure 2. The sign test indicates that the median concentration values recorded by the three sampler models differ significantly for both pollen taxa, with the exception of the Rotorod and 7-Day sampler for

Table 1. Descriptive statistics for the Urticaceae $(n=40)$ and Poaceae $(n=45)$ data sets. 'Ratio' means the ratio of concentrations recorded by the two indicated samplers

\begin{tabular}{|c|c|c|c|c|c|}
\hline \multirow[b]{2}{*}{ Variable } & \multirow[b]{2}{*}{ Units } & \multicolumn{2}{|c|}{ Urticaceae } & \multicolumn{2}{|c|}{ Poaceae } \\
\hline & & Range & Median & Range & Median \\
\hline $\begin{array}{l}\text { 7-Day sampler } \\
\text { concentration }\end{array}$ & grains $\mathrm{m}^{-3}$ & $30.3-575.6$ & 190.9 & $85.5-461.5$ & 145.3 \\
\hline $\begin{array}{l}\text { Rotorod } \\
\text { concentration }\end{array}$ & grains $\mathrm{m}^{-3}$ & $13.5-479.8$ & 142.8 & $45.4-565.0$ & 156.0 \\
\hline PVAS concentration & grains $\mathrm{m}^{-3}$ & $5.2-215.5$ & 51.7 & $22.4-234.5$ & 48.3 \\
\hline $\begin{array}{l}\text { Rotorod/7-Day } \\
\text { sampler ratio }\end{array}$ & - & $0.36-1.56$ & 0.73 & $0.44-1.55$ & 1.05 \\
\hline $\begin{array}{l}\text { PVAS/7-Day sampler } \\
\text { ratio }\end{array}$ & - & $0.08-0.84$ & 0.28 & $0.14-1.25$ & 0.35 \\
\hline PVAS/Rotorod ratio & - & $0.12-0.96$ & 0.37 & $0.19-0.99$ & 0.39 \\
\hline Wind speed & $\mathrm{ms}^{-1}$ & $0.65-4.25$ & 2.33 & $0.74-3.45$ & 1.88 \\
\hline Relative humidity & $\%$ & $45.5-76.5$ & 60.4 & $40.2-80.6$ & 52.0 \\
\hline
\end{tabular}

Table 2. Results of the two-tailed sign test on pollen concentration data for the different sampler pairings and pollen taxa

\begin{tabular}{llcc}
\hline \multicolumn{1}{c}{ Pollen taxa } & \multicolumn{1}{c}{ Comparison } & Test statistic & p-value \\
\hline \multirow{2}{*}{ Urticaceae } & Rotorod \& 7-Day & 5 & $<0.0001^{*}$ \\
\cline { 2 - 4 } & PVAS \& 7-Day & 0 & $<0.0001^{*}$ \\
\cline { 2 - 4 } & PVAS \& Rotorod & 0 & $<0.0001^{*}$ \\
\hline \multirow{2}{*}{ Poaceae } & Rotorod \& 7-Day & 21 & 0.7660 \\
\cline { 2 - 4 } & PVAS \& 7-Day & 1 & $<0.0001^{*}$ \\
\cline { 2 - 4 } & PVAS \& Rotorod & 0 & $<0.0001^{*}$ \\
\hline
\end{tabular}

* - indicates sampler pairings for which median concentrations were found to differ significantly

Poaceae pollen (Tab. 2). Concentrations recorded with the PVAS tend to be lower than those recorded with the 7-Day sampler or Rotorod for both pollen taxa. Concentration data are significantly correlated for all sampler combinations and both pollen taxa. For both taxa the strongest correlation occured for the Rotorod/7-Day sampler pairing. For each sampler pairing, a stronger correlation coefficient is found with Urticaceae pollen than with Poaceae pollen (Tab. 3).

Relative efficiencies for sampler pairings involving the PVAS (PVAS/7-Day sampler and PVAS/Rotorod) were significantly negatively correlated with wind speed for both pollen taxa (Tab. 4, Fig. 3). These relationships were stronger

Table 3.Spearman's correlation coefficients between pollen concentration measurements for all sampler pairings and both pollen taxa. Italic font indicates Urticaceae pollen and bold font indicates Poaceae pollen. All relationships were significant, with one-tailed $p$-values $<0.0001$

\begin{tabular}{lccc}
\hline & 7-Day & Rotorod & PVAS \\
\hline 7-Day & - & 0.916 & 0.835 \\
\hline Rotorod & $\mathbf{0 . 8 4 6}$ & - & 0.829 \\
\hline PVAS & $\mathbf{0 . 6 2 2}$ & $\mathbf{0 . 7 8 7}$ & -
\end{tabular}

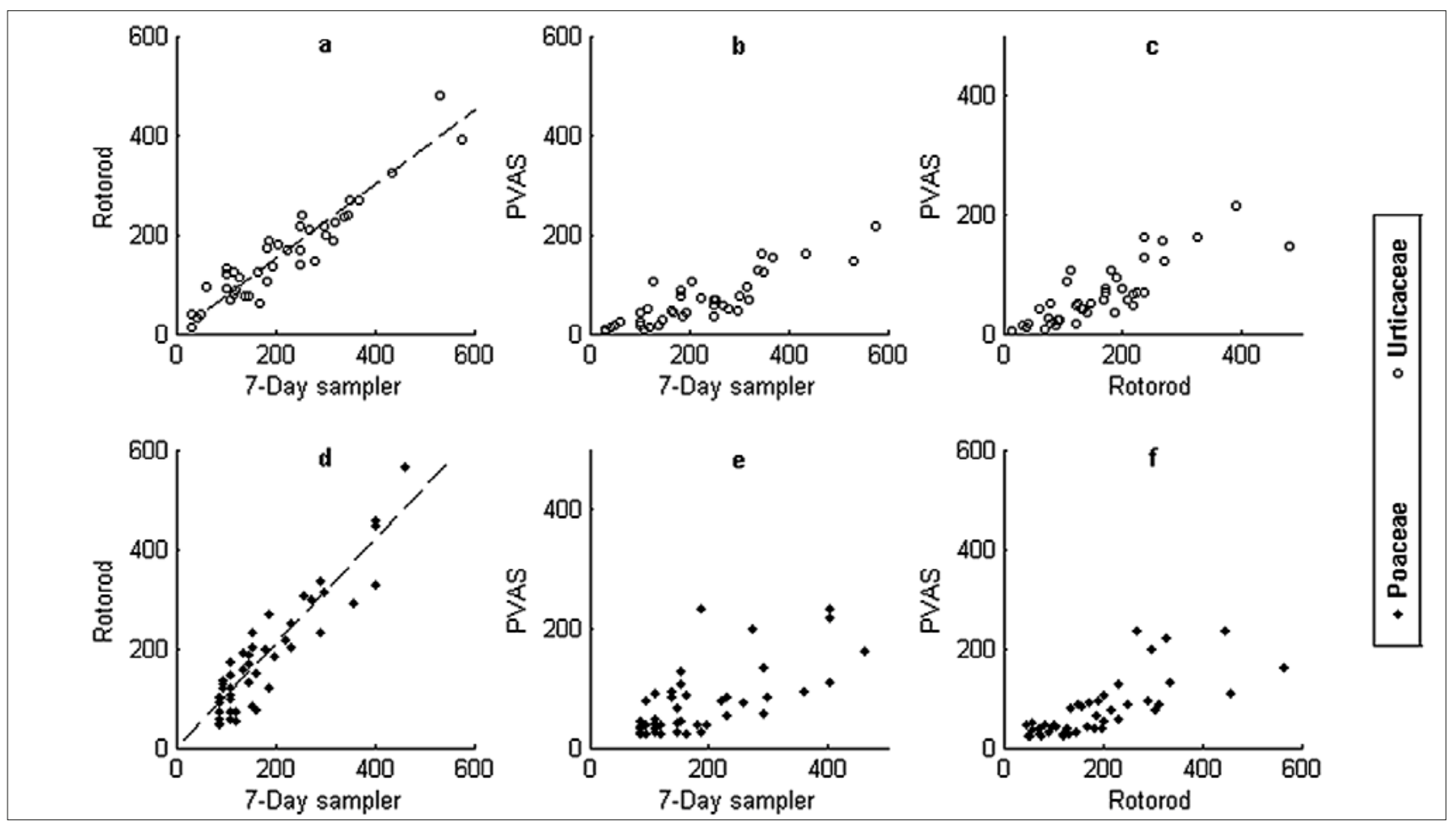

Figure 2. Scatter plots of concentration data (grains $\mathrm{m}^{-3}$ ) for the three sampler pairings and two pollen taxa. Urticaceae data are presented in Fgures a, $b$ and $c$, and Poaceae data in Fgures d, e and f. Geometric mean regression lines are plotted for the Rotorod/7-Day sampler pairings. Line equations are (a) $y=0.7505 x$ and (d) $y=1.0498 x$ 


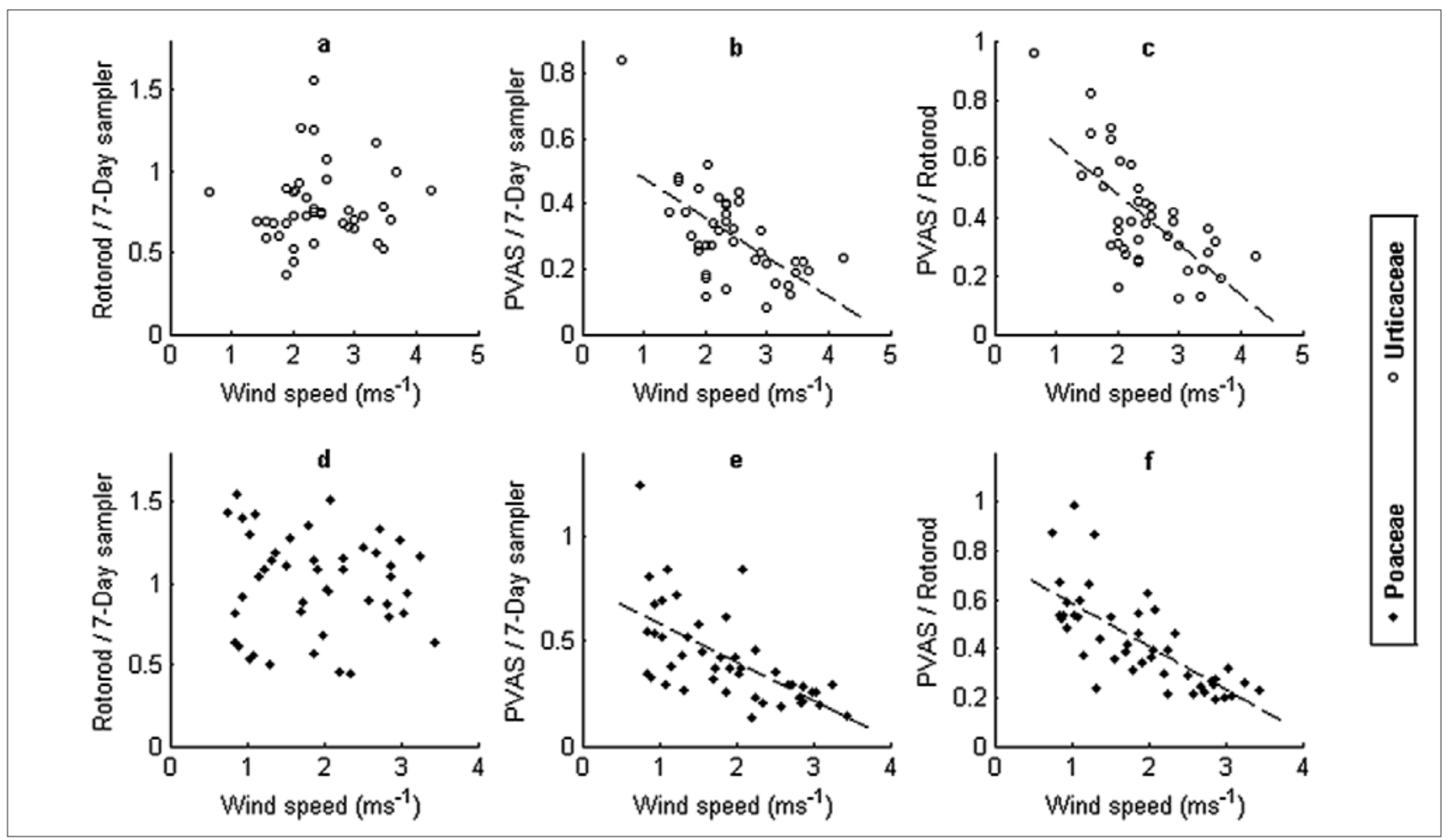

Figure 3. Scatter plots of wind speed against pollen concentration ratio for the three sampler pairings and two pollen taxa. Urticaceae data are presented in Figures a, $b$ and $c$, and Poaceae data in Figures d, e and f. Ordinary least squares regression lines are plotted for the significant relationships (those involving the PVAS) Line equations are (b) $y=-0.1218 x+0.6001$, (c) $y=-0.1732 x+0.8232$, (e) $y=-0.1828 x+0.7658$, and (f) $y=-0.1792 x+0.7683$

Figures b, c, e and f all hint at a non-linear relationship; however, there was judged to be insufficient range in the wind speed data for a curve to be reliably fitted

Table 4. Spearman's correlation coefficients for pollen concentration ratios and meteorological variables

\begin{tabular}{lllll}
\hline Pollen taxa & \multicolumn{1}{c}{ Variable } & Rotorod/7-Day & PVAS/7-Day & PVAS/Rotorod \\
\hline \multirow{2}{*}{ Urticaceae } & Wind speed & 0.193 & $-0.517^{*}$ & $-0.613^{*}$ \\
\cline { 2 - 5 } & Relative humidity & 0.065 & -0.048 & -0.121 \\
\hline \multirow{2}{*}{ Poaceae } & Wind speed & -0.063 & $-0.705^{*}$ & $-0.782^{*}$ \\
\cline { 2 - 5 } & Relative humidity & 0.121 & 0.254 & 0.157 \\
\hline
\end{tabular}

*-indicates a significant two-tailed $p$-value (in all such cases $p \leq 0.001$ )

for Poaceae pollen $\left(r_{s}=0.71,0.78\right)$ than for Urticaceae $\left(r_{s}=\right.$ $0.52,0.61)$, and for both taxa this relationship was stronger for the PVAS/Rotorod pairing than for the PVAS/7-Day sampler pairing. No significant correlations were found between concentration ratios and relative humidity.

The regression equations presented in Figures 2 and 3 were rearranged to produce mathematical relationships that convert concentrations measured with the Rotorod $\left(C_{\text {rotorod }}\right)$ and PVAS $\left(C_{\text {pvas }}\right)$ to the value expected from a 7-Day sampler operating under identical conditions $\left(\hat{C}_{7-\text { day }}\right)$, and for converting PVAS concentrations into the value expected from a Rotorod operating under identical conditions $\left(\hat{C}_{\text {rotorod }}\right)$. For Urticaceae pollen these inter-sampler conversion factors (RMSE) are:

$$
\begin{aligned}
& \hat{\mathrm{C}}_{7-\text { day }}=1.3324 \times C_{\text {rotorod }} \\
& \hat{\mathrm{C}}_{\text {7-day }}=\frac{C_{\text {pvas }}}{0.6001-0.1218 u} \\
& \hat{\mathrm{C}}_{\text {rotorod }}=\frac{C_{\text {pvas }}}{0.8232-0.1732 u}
\end{aligned}
$$

where $\mathrm{u}$ is wind speed in $\mathrm{ms}^{-1}$. The conversion factors (RMSE) for Poaceae pollen are

$$
\begin{aligned}
\hat{\mathrm{C}}_{7-\text { day }} & =0.9525 \times C_{\text {rotorod }} \\
\hat{\mathrm{C}}_{7-\text { day }} & =\frac{C_{\text {pvas }}}{0.7658-0.1828 u} \\
\hat{\mathrm{C}}_{7-\text { day }} & =\frac{C_{\text {pvas }}}{0.7683-0.1792 u}
\end{aligned}
$$

All concentrations are in units of grains $\mathrm{m}^{-3}$.

\section{DISCUSSION}

Absolute efficiency. The three samplers compared in this study may be classified as impaction devices, so-called because particles are removed from the air following impaction against an adhesive surface. The efficiency of impaction samplers depends upon how closely target aerosol particles follow air streamlines during changes in speed and direction. This depends upon a number of the particle's physical properties, namely, size, shape, density [34] and surface roughness [5]. Both Urticaceae and Poaceae pollen are smooth and approximately spherical [35] but differ considerably in size, with Urticaceae typically $12-17 \mu \mathrm{m}$ [36] and the pollen grains of common Poaceae taxa typically 20-40 $\mu \mathrm{m}$ in diameter [37]. Furthermore, Poaceae pollen tends to be denser than Urticaceae pollen [38]. The larger, denser Poaceae pollen grains are less responsive to the speed and direction changes that mediate sampler efficiency, which accounts for the stronger correlation coefficients for Urticaceae than for Poaceae. 
There are two principle components to the overall efficiency of suction impactors such as the 7-Day sampler and PVAS: aspiration efficiency, the efficiency with which particles are transferred from ambient air into the sampler's inlet, and impaction efficiency, the efficiency with which aspirated particles are impacted against the collection substrate. Impaction efficiency varies with particle aerodynamic diameter [39] and therefore can be expected to be approximately constant for a particular pollen taxa. In this study, variation in sampler efficiency is therefore assumed to relate solely to aspiration efficiency.

Aspiration efficiency is sensitive to changes in the speed and direction of air as it enters the sampler's inlet [40]. The inlet of the 7-Day sampler is horizontally-orientated and faces approximately into the wind, however a difference between ambient air speed and the flow rate through the sampler's inlet causes air to accelerate or decelerate as it enters the sampler. This serves to artificially increase respectively decrease measured particulate concentrations, particularly with respect to larger particles [13]. Wind tunnel studies have shown that the efficiency of Hirst-type samplers varies quadratically with wind speed, but for Phleum pollen and wind speeds in the range $2-6 \mathrm{~ms}^{-1}$ it is largely invariant, ranging from $65-71 \%$. No data on Urticaceae-sized particles appear to be available, however; for the same wind speed range, efficiency is higher for Ustilago spores $(7.5 \mu \mathrm{m})$ at between $78-97 \%$ [13].

The vertical orientation of the PVAS means that as horizontal wind speed increases, air is forced to turn more violently as it enters the sampler's inlet. The proportion of particles that deviate from air streamlines enough to evade capture will also increase, causing aspiration efficiency to decline [13]. This explains why the PVAS was associated with weaker correlations between concentration data and with stronger correlations between concentration ratios and wind speed.

Rotating arm impactors, like suction samplers, remove particles from the air by exploiting their inertial properties [3]. Efficiency increases as particle diameter and density increase, with smaller lighter particles more able to follow air streamlines around the moving rods, and larger heavier particles more likely to collide and become trapped. Within the pollen size range, the effects of particle aerodynamic properties have opposing effects on suction and rotating arm sampler efficiency, with particles that are more readily captured by the former able to evade the latter more effectively [5]. Rotating arm devices are generally considered to be suitable for sampling particles greater than $10 \mu \mathrm{m}$ in diameter. At around 12-17 $\mu \mathrm{m}$ [36], Urticaceae pollen is close to this threshold diameter, thus it is not surprising that the Rotorod records relatively lower Urticaceae than Poaceae pollen concentrations when compared with the 7-Day sampler. Results from laboratory and field studies that do not account for wind speed effects, suggest that the efficiency of rotating arm devices for grass pollen sized particles lies in the range $85-93 \%[16,40]$, while under laboratory conditions an efficiency of $54.9 \%$ is reported for paper mulberry pollen, which at $11-13 \mu \mathrm{m}$ is slightly smaller than Urticaceae pollen [41]. A best approximation based on existing experimental data then suggests that for Poaceae pollen the Rotorod should be some $20-43 \%$ more efficient than the 7-Day sampler. In this study, the Rotorod was found to be only $5 \%$ more efficient.
After release from the anthers, pollen grains exposed to air dry out until an equilibrium water content is reached. The rate of desiccation and the equilibrium value itself depend upon ambient relative humidity. Zea mays pollen exposed to $20 \%$ relative humidity was found at equilibrium to have lost $95.6 \%$ of its water content after just 1 hour. Even exposure to $75 \%$ relative humidity resulted in an $84.3 \%$ loss of water after around 4 hours. Drying is accompanied by transformation from oblate spheroidal to crinkled prismatic shape, and a $16 \%$ increase in density $[18,19]$. These changes are accompanied by a $34 \%$ reduction in settling velocity, indicating that the ability of pollen grains to follow air streamlines increases as relative humidity decreases, which would be expected to have a positive effect on the efficiency of the two suction devices and a negative effect on Rotorod efficiency. However, no evidence for such a phenomenon was found in this study, indicating that relative humidities within the range observed during this study have a negligible effect on sampler efficiency. It is possible that an association could become evident in a larger data set collected under a greater range of relative humidity values.

Relative efficiency. Although the authors are not aware of any published work concerning either Poaceae or Urticaceae pollen that addresses the relative efficiencies of the three samplers considered here, a number of such studies exist for other bioaerosol particles, and these provide at least some possibility for validating the results of the present study.

Rotorod/7-Day sampler. Field comparisons have found rotating arm samplers to be $37 \%$ as efficient as Hirst-type samplers for Venturia inaequalis spores [15], and 53\% as efficient for Ambrosia pollen [24]. Venturia inaequalis spores are thin and elongate, with typical dimensions of $20.5 \times 6.5 \mu \mathrm{m}$ [42], whereas Ambrosia pollen is spheroidal, $17-24 \mu \mathrm{m}$ in diameter and covered with small spines [35]. Urticaceae pollen is smaller than both of these taxa but was associated with a greater relative efficiency (75\%). Particles that are non-spheroidal or rough incur greater drag than do their smooth, spherical counterparts [5]. This would be expected to favour 7-Day sampler efficiency but suppress Rotorod efficiency, which likely accounts for the sizeable discrepancies between the results of previous work and this study.

PVAS/7-Day sampler. Equations 2 and 5 imply that as wind speed increases from ${ }^{2} 1.5$ to $3 \mathrm{~ms}^{-1}$, PVAS efficiency declines from $42 \%$ to $23 \%$ that of the 7 -Day sampler for Urticaceae pollen, while for Poaceae pollen the corresponding decline is from $49 \%-22 \%$. Given that 7 -Day sampler efficiency is thought to be largely invariant over the majority of this interval, it seems appropriate to attribute this decline to a reduction in PVAS efficiency. Qualitatively equivalent results have been obtained for a vertically-orientated Air-O-Cell for birch pollen $(22 \mu \mathrm{m})$, although relative concentrations were far lower due to the effect of the Air-O-Cell's sharp inlet on local airflow [43].

PVAS/Rotorod. Equations 3 and 6 imply that PVAS efficiency declines from $56 \%$ to $30 \%$ that of the 7 -Day sampler for

2. The rounded intersection of wind speed ranges corresponding to both Urticaceae and Poaceae collection. 
Urticaceae pollen, and from $50 \%$ to $23 \%$ for Poaceae pollen as wind speed increases from 1.5 to $3 \mathrm{~ms}^{-1}$, reflecting the fact that the Rotorod is approximately as efficient as the 7-Day sampler for Poaceae pollen, but less efficient for Urticaceae pollen. Qualitatively similar results have been obtained for an Allergenco MK-2 sampler (a similar device to the PVAS) and Pinaceae pollen during wind tunnel studies [44]. In a laboratory study with a stable $0.6 \mathrm{~ms}^{-1}$ wind, the mean Ambrosia pollen concentration recorded by the PVAS was found to be 2.1 times greater than that recorded by a Sampling Technologies Model 85 Rotorod [45], i.e. nearly 4 times the value that the results of this study found under a $1.5 \mathrm{~ms}^{-1}$ wind for both Urticaceae and Poaceae pollen. PVAS relative efficiency clearly increases as wind speed decreases, while, as previously noted, the spiny surface of Ambrosia pollen would be expected to have a positive effect on PVAS efficiency and a negative effect on Rotorod efficiency. It is not clear whether these two factors would be sufficient to account for the magnitude of this discrepancy.

Inter-sampler conversion factors. Equations 1-6 may be used to convert concentration measurements made with one type of sampler to the value expected from another type operating under identical conditions, thus allowing data collected with different instruments to be compared directly. Extreme caution should be taken when using these conversions for particles other than those for which they were derived. It is recommended that these conversions are not used for wind speeds outside these ranges without strong justification.

Although the RMSEs for these conversions are not small, ranging from $29-47 \%$, we would not expect two identical samplers standing next to one another to record the same concentration. The RMSE between the collector rod pairs in the Urticaceae study (difference scaled by mean) was $12.73 \%$, while for birch pollen RMSEs of $38 \%$ and $57 \%$ have been reported, respectively, for pairs of 7-Day samplers and vertically-orientated Air-O-Cell samplers mounted in a compact array [43]. The errors associated with the corrections presented in the current study are therefore acceptable when compared with the precision errors of the individual instruments.

Although the Hirst-type sampler does not collect particles with perfect efficiency [13], as the industry standard bioaerosol sampler it has become the reference device upon which pollen forecasts and exposure estimates are typically based. Intersampler efficiency corrections, such as those presented in this study, allow data collected with different types of sampler to be converted into a common exposure assessment metric. In this way, the fidelity of epidemiological or other clinical studies may be improved.

\section{CONCLUSIONS}

Although the Urticaceae and Poaceae concentration data collected with the 7-Day sampler, Rotorod and PVAS were strongly correlated, the three devices recorded significantly different concentrations, with the exception of the 7-Day sampler and Rotorod pairing for Poaceae pollen. This means that data collected with different devices must be adjusted using inter-sampler conversion factors before a direct comparison is possible. Relative efficiencies involving the PVAS are significantly affected by wind speed, and this must be taken into account in conversion factor formulation. Relative humidity was not found to affect relative efficiencies for any of the sampler combinations or pollen taxa over the range of values observed during this study. Correction factors that allow for the comparison of Poaceae and Urticaceae data collected with the 7-Day, Rotorod and PVAS samplers are presented.

\section{Acknowledgements}

The lead author would like to extend special thanks to Janne Sommer at Astma-Allergi Danmark for her unquestioning generosity in providing access to data and facilities, and to Dr. Harry Morrow Brown for his advice and loan of equipment.

\section{REFERENCES}

1. Hirst JM. An automatic volumetric spore trap. Ann Appl Biol. 1952; 39(2): 257-265.

2. Emberlin J, McCartney A. Monitoring atmospheric allergenicity - an alternative to pollen and spore counting. In: Emberlin J, Tariq SM, editors. Clinical Applications of Aerobiology. Braine-l'Alleud, D. Van Moerbeke for The UCB Institute of Allergy, 1996.p.57-67.

3. Muilenberg ML. Sampling devices. Immunol Allergy Clin North Am. 2003; 23: 337-355

4. Galán Soldevilla C, Cariñanos González P, Alcázar Teno P, Domínguez Vilches E. Spanish aerobiology network (REA): management and quality manual. Córdoba, Servicio de Publicaciones de la Universidad de Córdoba, 2007

5. Solomon WR. How ill the wind? Issues in aeroallergen sampling. J Allergy Clin Immunol. 2003; 112(1): 3-8.

6. Di-Giovanni F. A review of the sampling efficiency of rotating-arm impactors used in aerobiological studies. Grana 1998; 37(3): 164-171.

7. Feliziani V, Marfisi R. Pollen aerobiological monitoring with the personal volumetric air sampler (PVAS). Correlation with a fixed Hirst type sampling station. Aerobiologia 1992; 8(3): 471-477.

8. Mitakakis TZ, Tovey ER, Xuan W, Marks GB. Personal exposure to allergenic pollen and mould spores in inland New South Wales, Australia. Clin Exp Allergy. 2000; 30(12): 1733-1739.

9. O'Meara TJ, Green BJ, Sercombe JK, Tovey ER. Interpretation of pollen exposure data. J Allergy Clin Immunol. 2004; 113(2): 62-63.

10. O’Rourke MK, Lebowitz MD. A comparison of regional atmospheric pollen with pollen collected at and near homes. Grana 1984; 23(1): 55-64.

11. Riediker M, Keller S, Wüthrich B, Koller T, Monn C. Personal pollen exposure compared to stationary measurements. J Investig Allergol Clin Immunol. 2000; 10(4): 200-203.

12. Vincent JH. Aerosol sampling: science, standards, instrumentation and applications. 1st ed. Chichester, John Wiley \& Sons Ltd., 2007.

13. Ogden EC, Raynor GS, Hayes JV, Lewis DM, Haines JH. Manual for sampling airborne pollen. 1st ed. New York, Hafner Press, 1974.

14. Frenz DA. The effect of windspeed on pollen and spore counts collected with the Rotorod Sampler and Burkard spore trap. Ann Allergy Asthma Immunol. 2000; 85(5): 392-394.

15. Aylor DE. Relative collection efficiency of Rotorod and Burkard spore samplers for airborne Venturia inaequalis ascospores. Phytopathology. 1993; 83(10): 1116-1119.

16. May KR, Pomeroy NP, Hibbs S. Sampling techniques for large windborne particles. J Aerosol Sci. 1976; 7(1): 53-62.

17. D’Amato G, Cecchi L, Bonini S, Nunes C, Annesi-Maesano I, Behrendt $\mathrm{H}$, et al. Allergenic pollen and pollen allergy in Europe. Allergy 2007; 62(9): 976-990.

18. Aylor DE. Settling speed of corn (Zea mays) pollen. J Aerosol Sci. 2002; 33(11): 1601-1607.

19. Aylor DE. Rate of dehydration of corn (Zea mays L.) pollen in the air. J Exp Bot. 2003; 54(391): 2307-2312.

20. Durham OC. The volumetric incidence of atmospheric allergens I: specific gravity of pollen grains. J Allergy. 1943; 14(6): 455-461.

21. British Aerobiology Federation. Airborne pollens and spores: a guide to trapping and counting. British Aerobiology Federation, 1994.

22. Fiorina A, Scordamaglia A, Mincarini M, Fregonese L, Canonica GW. Aerobiologic particle sampling by a new personal collector (Partrap 
FA52) in comparison to the Hirst (Burkard) sampler. Allergy 1997; 52(10): 1026-1030.

23. Levetin E, Rogers CA, Hall SA. Comparison of pollen sampling with a Burkard spore trap and a Tauber trap in a warm temperate climate. Grana 2000; 39(6): 294-302.

24. Solomon WR, Burge HA, Boise JR, Becker M. Comparative particle recoveries by the Retracting Rotorod, Rotoslide and Burkard spore trap sampling in a compact array. Int J Biometeorol. 1980; 24(2): 107-116.

25. Alcázar P, Comtois P. The influence of sampler height and orientation on airborne Ambrosia pollen counts in Montreal. Grana 2000; 39(6): 303-307.

26. Levetin E, Shaughnessy R, Fisher E, Ligman B, Harrison J, Brennan T. Indoor air quality in schools: exposure to fungal allergens. Aerobiologia 1995; 11(1): 27-34.

27. Hugg T, Valtonen A, Rantio-Lehtimäki A. Pollen concentrations inside private cars during the Poaceae and Artemisia spp. pollen season - a case study. Grana 2007; 46(2): 110-117.

28. Jantunen J, Saarinen K. Intrusion of airborne pollen through open windows and doors. Aerobiologia. 2009; 25(3): 193-201.

29. Sterling DA, Lewis RD. Pollen and fungal spores indoor and outdoor of mobile homes. Ann Allergy Asthma Immunol. 1998; 80(3): 279-285

30. Sampling Technologies. Operating instructions for the Rotorod sampler. Minnetonka, MN, Sampling Technologies Inc., 1998.

31. Warner FE, McCartney HA, Emberlin J. Wind tunnel comparison of the collection efficiency of three Hirst-type volumetric sampler drum coatings. Aerobiologia. 2000; 16(1): 25-28.

32. Leng L, Zhang T, Kleinman L, Zhu W. Ordinary least square regression, orthogonal regression, geometric mean regression and their applications in aerosol science. J Phys Conf Ser. 2007; 78: 01284.

33. MATLAB. MATLAB version 7.7.0.471 (R2008b). Natick, MA, The MathWorks, Inc., 2008.
34. Mandrioli P. Introduction to biological particles. In: Mandrioli P, Comtois P, Levizzani V (Eds.). Methods in aerobiology. 1st ed. Bologna, Pitagora Editrice 1998.p.1-12.

35. Wodehouse RP. Pollen grains: their structure, identification and significance in science and medicine. Facsimile of 1st ed. New York, Hafner Publishing Company, 1965.

36. Hyde HA, Adams KF. An atlas of airborne pollen grains. 1st ed. London, Macmillan \& Co Ltd, 1958.

37. Morrow Brown H, Irving KR. The size and weight of common allergenic pollens. Acta Allergol. 1973; 28: 132-137.

38. Durham OC. The volumetric incidence of atmospheric allergens: III. Rate of fall of pollen grains in still air. J Allergy. 1946; 17(2): 70-78.

39. Aizenberg V, Reponen T, Grinshpun SA, Willeke K. Performance of Air-O-Cell, Burkard, and Button samplers for total enumeration of airborne spores. AIHAJ. 2000; 61: 855-864.

40. Buttner MP, Willeke K, Grinshpun SA. Sampling and analysis of airborne microorganisms. In: Hurst CJ, Knudsen GR, McInerney MJ, Stetzenbach LD, Walter MV (Eds.). Manual of Environmental Microbiology. 1st ed. Washington DC, ASM Press 1997.p.629-640.

41. Magill PL, Lumpkins ED, Arveson JS. A system for appraising airborne populations of pollens and spores. Am Ind Hyg Assoc J. 1968; 29(3): 293-298.

42. Ellis MB. Dematiaceous Hyphomycetes. 1st ed. Kew, Surrey, Commonwealth Mycological Institute, 1971.

43. Michel D, Rotach MW, Gehrig R, Vogt R. On the efficiency and correction of vertically orientated blunt bioaerosol samplers in moving air. Int J Biometeorol. 2012; 56(6): 1113-1121.

44. Banks L, Di Giovanni F. A wind tunnel comparison of the Rotorod and Samplair pollen samplers. Aerobiologia 1994; 10(2): 141-145.

45. Heffer MJ, Ratz JD, Miller JD, Day JH. Comparison of the Rotorod to other air samplers for the determination of Ambrosia artemisiifolia pollen concentrations conducted in the Environmental Exposure Unit. Aerobiologia 2005; 21(3-4): 233-239. 